\title{
Vehicle Speed Characteristics and Alignment Design Consistency for Mountainous Roads
}

\author{
Suresh Nama ${ }^{1} \cdot$ Akhilesh K. Maurya $^{1} \cdot$ Avijit Maji $^{2} \cdot$ Praveen Edara $^{3} \cdot$ \\ Prasanta K. Sahu ${ }^{4}$
}

Received: 4 October 2015/Accepted: 8 September 2016/Published online: 22 September 2016

(c) Springer International Publishing Switzerland 2016

\begin{abstract}
Vehicle drivers continuously make decisions and execute them while driving on a roadway. It requires perception, comprehension and prediction of roadway conditions. Studies show that the decision-making process and driver performance greatly depends on situational awareness. Drivers intend to operate vehicles at safe speed based on the roadway geometric features. These features are characterized by gradient, horizontal curvature, length of curves and tangent sections, superelevation, etc. Perceptive and consistent geometric characteristics of the roadway can ease the decision making burden and thus minimize driver error. So far, majority of the studies on geometric design consistency are conducted on isolated curve sections in plain terrain for traffic with strong lane discipline. The effect of gradient is not significant in these terrains. Further, the driving behavior of traffic with weak lane discipline is not represented in these studies. Hence, the aim of this paper is to study geometric consistency of roadways on mountainous terrain for traffic with weak lane discipline characteristics using existing consistency based safety evaluation methods. Isolated horizontal curves with horizontal curvature, length of curve and gradient are considered for the purpose. Sixteen sites in a mountainous terrain with distinct horizontal alignment and vertical profile features are chosen on a four-lane divided National Highway 40 in India. The obtained results indicate that $79 \%$ and
\end{abstract}

Avijit Maji

avijit.maji@gmail.com

Indian Institute of Technology Guwahati, Guwahati, India

Indian Institute of Technology Bombay, Mumbai, India

3 University of Missouri-Columbia, Columbia, USA

4 Birla Institute of Technology \& Science, Pilani, India
$93 \%$ locations exhibit good level of consistency as per Lamm's Criteria I and Criteria II, respectively. It is also observed that average vehicle operating speed at most of the locations exceeds the design speed.

Keywords Geometric design consistency · Horizontal curve Vertical gradient $\cdot 85$ th percentile speed .

Mountainous terrain

\section{Introduction}

Vehicles have higher crash risk at horizontal curve sections of roadways in mountainous terrain. Simultaneous change in vertical profile and horizontal alignment makes it critical. The crash risk further increases for inconsistent change in roadway geometric features. Hence, maintaining geometric consistency in mountainous terrain is crucial for road safety. Geometric consistency is evaluated using surrogate measures such as, operating speed, vehicle stability, alignment indices and driver workload [1]. Though roadway geometric features are designed on the basis of vehicle design speed [2], vehicle operating speed is the better performance measure to assess driving behavior and geometric consistency. Vehicle operating speed at tangent section depends on gradient and cross sectional geometry [3]. On the other hand, operating speed on isolated horizontal curves is highly influenced by its length, radius and approach tangent section [4].

Praticò and Giunta [5] stated that the variance of operating speed on mountainous terrain is as high as $55 \%$. This is because of the combined effect of horizontal and vertical geometric features. Driver's basic expectation at horizontal curves is to operate the vehicle at safe consistent speed with reasonable mental workload [6]. Vertical gradient in 
the horizontal curves introduces additional burden of maintaining consistent speed. Also, the horizontal curves look sharper when overlapped with crest curves and flatter when overlapped with sag curves [7]. Research shows that vehicle operating speed changes significantly on horizontal curve of radius $250 \mathrm{~m}$ or less; whereas, it is negligible on radius more than $400 \mathrm{~m}$ [8]. Hence, several studies considered radius of curvature within the range of 30-100 m, while developing operating speed prediction models for horizontal curves [4, 9, 10].

The tangent sections between the curves help drivers to perceive and react on the approaching curve [11]. However, roadways in mountainous terrain have frequent horizontal curves with and sometime without adequate preceding tangent section. Drivers in India predominantly drive in mixed traffic conditions. This situation leads to weak lane discipline among drivers. In absence of other vehicles, these drivers have tendency to use the full carriageway width while negotiating a horizontal curve section. Therefore, this study attempts to understand the behavior of Indian drivers in roadways on mountainous terrain. The combined effect of curves and gradients is considered in the process. Overall, the novelty of the proposed work is in the application of available consistency based safety evaluation methods on mountainous terrain roadways for Indian drivers with weak lane discipline characteristics.

In this paper, the operating speed of cars and trucks exposed to Indian driving condition is selected as surrogate performance measure for geometric consistency evaluation of roadways in mountainous terrain. The operating speed is defined as the uninterrupted speed chosen by a driver for the given driving environment such as, roadway geometry and vehicle type. For a driver population using the same facility, it is referred as the 85 th percentile free flow speed [12].

\section{Literature Review}

Hashim [13] developed a regression based model to estimate capacity loss between tangent and curved sections. This loss decreases as the radius of curve increases [13]. The main reason of capacity loss can be attributed to reduction in vehicle speed. It is also observed that the amount of speed dispersion of heavy vehicles is less than the lighter vehicles [14]. Lamm et al. [15] and Fitzpatrick et al. [16] used the differences between design speed and 85th percentile speed of a roadway section to evaluate geometric consistency and safety of two-lane rural highways. They explained geometric consistency between two consecutive sections (such as, approach tangent and center of the curve) by evaluating the difference in 85 th percentile
Table 1 Design consistency and safety evaluation criteria [15, 17]

\begin{tabular}{lll}
\hline Design safety & Criteria I $(\mathrm{kmph})$ & Criteria II $(\mathrm{kmph})$ \\
\hline Good & $\left|\mathrm{V}_{85}-\mathrm{V}_{\mathrm{d}}\right| \leq 10$ & $\lambda \mathrm{V}_{85} \leq 10$ \\
Fair & $10<\left|\mathrm{V}_{85}-\mathrm{V}_{\mathrm{d}}\right| \leq 20$ & $10<\lambda \mathrm{V}_{85} \leq 20$ \\
Poor & $\left|\mathrm{V}_{85}-\mathrm{V}_{\mathrm{d}}\right|>20$ & $\lambda \mathrm{V}_{85}>20$ \\
\hline
\end{tabular}

passenger car speed at these sections. Similar study on Indian traffic condition for two-lane roadway with gradients varying between \pm 2 percentages is also available [17]. The speed difference criteria considered in these studies is given in Table 1. Apart from differences in 85 th percentile speed, researchers have used 85th percentile speed differential [18], design consistency quality [19], etc. However, these studies do not consider the combined effect of vertical gradient and horizontal curvature that is commonly witnessed in a mountainous terrain.

Majority of the published studies on geometric design consistency are focused on isolated horizontal curves for two-lane bidirectional rural roadways in plane terrain with maximum $2 \%$ gradient $[4,6,8,10]$. Though spot speed is the most commonly used speed data in these studies, the global positioning system (GPS) based speed profile is not uncommon [18, 19]. However, the GPS based speed profile data can be biased (since driver's are aware of the invehicle GPS) and may not be the true representation of the driver population (only a few selected drivers are asked to drive vehicle fitted with GPS). Except one [17], most of these studies are limited to homogeneous traffic mix $[4,9,10,15,16,18]$. In India, there is a wide variation in vehicle size, power to weight ratio, top speed, etc. Moreover, lane discipline among Indian drivers is not very strong. This makes the Indian traffic and driving condition different. Therefore, in this study, roadway sections with horizontal curves and gradients on a four-lane roadway located in the mountainous terrain of the Northeast region of India with bidirectional heterogeneous traffic mix are considered.

\section{Study Sites and Data}

In total, sixteen sites on the National Highway 40 (NH-40) connecting Guwahati and Shillong are chosen for this study. These sites varied in terms of radius, gradient and curve length. Field data required for this study are: (1) highway geometric data such as radius, gradient and length of the curve; and (2) vehicle speed data at entry, middle and exit of the curve locations (refer marked locations $\mathrm{A}, \mathrm{B}$ and $\mathrm{C}$ in Fig. 1). The vehicle speed data are collected at various sites in the month of April, 2015 between 8:00 AM and 6:00 PM. The selected sites are shown in Fig. 2. All 
sites (i.e., S1 to S16) are in mountainous terrain and are designed for $50 \mathrm{kmph}$ speed based on the design guideline IRC: 73-1980 [20]. Cars and trucks predominantly use the study area. Hence, in this study, consistency of geometric design is evaluated based on car and truck speed data.

A minimum of 50 speed data points per vehicle type at each location (i.e., A, B and C) are collected. In some locations the number of speed data per vehicle type are as high as 200 . These are the error free speed data obtained after filtering out the outliers. The vehicle speed data are

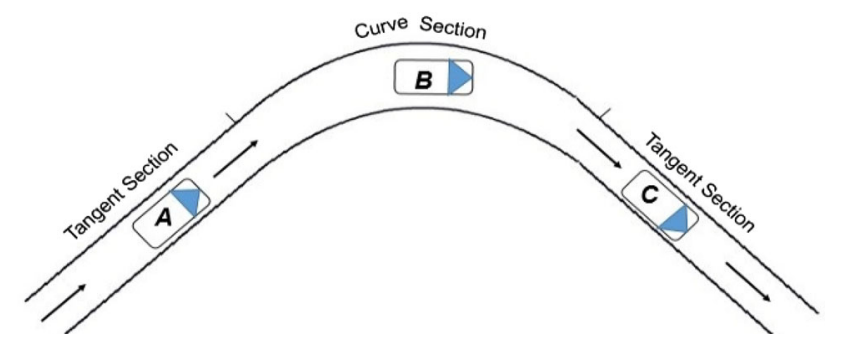

Fig. 1 Vehicle locations during data collection collected using radar gun and geometric data are obtained from the NH-40 drawings provided by the site engineer. The geometric data are verified in the field using laser distance meter (LDM) and found to be accurate. Table 2 summarizes the geometric data grouped in the interval of $50 \mathrm{~m}$ radius and $2 \%$ gradient. The curve radii at study sites vary from 50 to $300 \mathrm{~m}$ and gradients between \pm 6 percentages.

\section{Results and Analysis}

The obtained vehicle speed and geometric features are evaluated for design consistency based on the criteria provided in Table 1. Prior to the detail evaluation, preliminary analysis is conducted by plotting the cumulative frequency distributions of car and truck speed at various locations of the representative sites. Once the difference between car and truck speeds at various location of a curve is established, further statistical tests are carried out for its

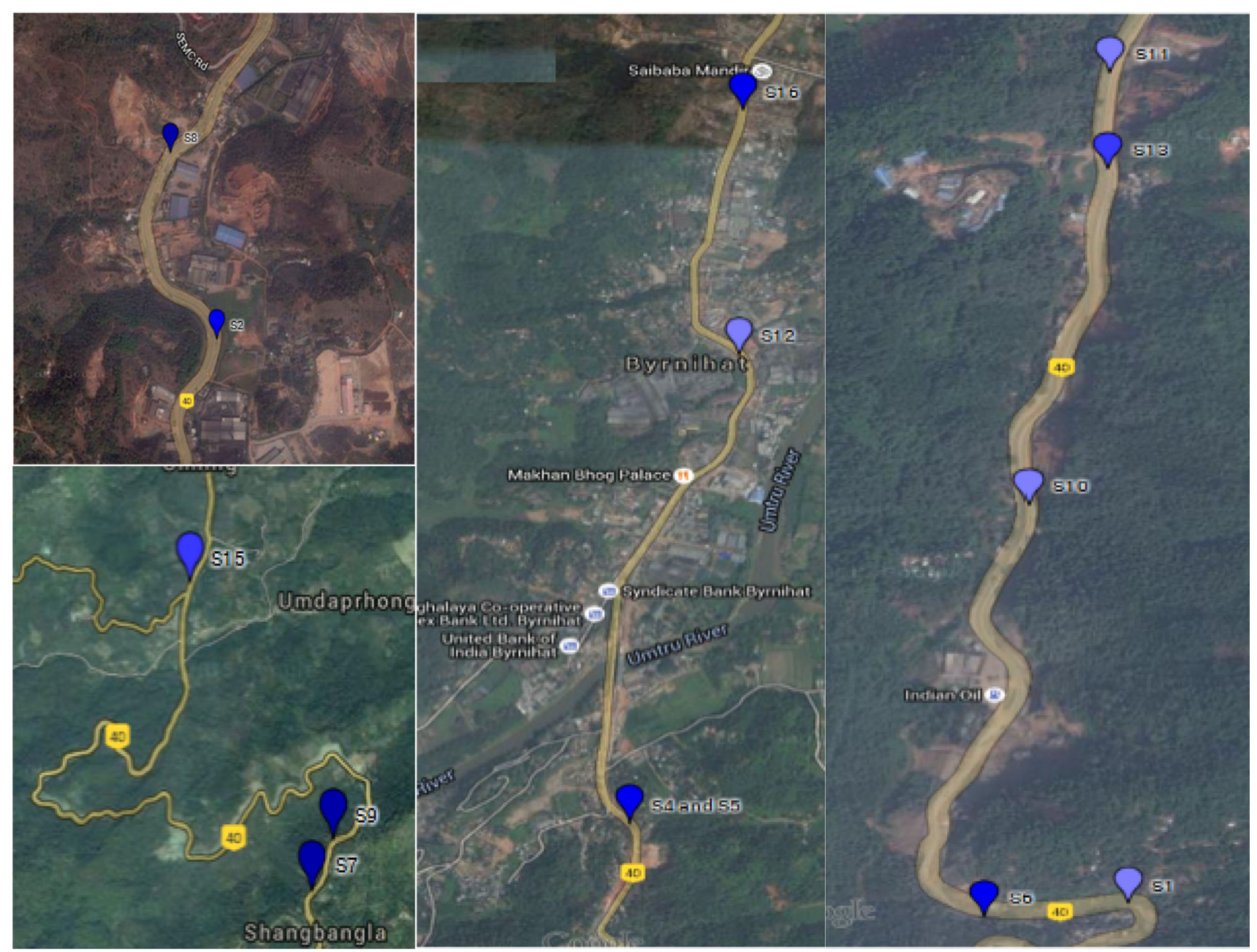

Fig. 2 Satellite view of study sites on Guwahati-Shillong Highway (NH-40) 
Table 2 Geometric features of the study sites

\begin{tabular}{lcrc}
\hline Site & Radius $(\mathrm{m})$ & Gradient $(\%)$ & Curve length $(\mathrm{m})$ \\
\hline S1 & 50 & 4 & 74 \\
S2 & 100 & -2 & 139 \\
S3 & 100 & 2 & 139 \\
S4 & 100 & -6 & 33 \\
S5 & 100 & 6 & 33 \\
S6 & 150 & -6 & 31 \\
S7 & 150 & -4 & 64 \\
S8 & 150 & 2 & 32 \\
S9 & 150 & 4 & 43 \\
S10 & 200 & -4 & 56 \\
S11 & 200 & -2 & 27 \\
S12 & 200 & 2 & 205 \\
S13 & 200 & 4 & 10 \\
S14 & 200 & 6 & 103 \\
S15 & 300 & -6 & 73 \\
S16 & 300 & 2 & 74 \\
\hline
\end{tabular}

probability distribution and other statistical parameters. This analysis is extended for the 85th percentile vehicle speed and geometric design consistency is evaluated at the end. The step by step data analysis process is discussed in the following sections.

\section{Preliminary Analysis of Speed Data}

The cumulative frequency distributions of speed at locations $\mathrm{A}, \mathrm{B}$ and $\mathrm{C}$ of a curve are analyzed to understand the influence of curvature and gradient on vehicle type. Plots of cumulative speed distribution of trucks and cars at four representative sites (i.e., S3, S5 S12 and S14) are shown in Fig. 3a, b, respectively. The details of site, type of vehicle and location are referred in the legends of each plot. For example, S3-TA in Fig. 3a refers to Site "S3" (i.e., site with radius $100 \mathrm{~m}$ and $+2 \%$ gradient) for vehicle type "T" ("T" for truck and " $C$ " for car) at location " $A$ " of the curve. These plots help to visualize the difference in vehicle speed at the beginning, middle and end of a horizontal curve with gradients. It is to be noted that speed data at all locations of a particular site are not available. These locations do not have suitable and safe space for vehicle data collection.

It can be observed from Fig. 3a, b that at milder ascending gradients (i.e., gradient between $0 \%$ to $2 \%$ ), truck and car speeds at the beginning of a curve (i.e., at location A) are lesser than the speeds at the end of a curve (i.e., at location C). However, at steeper ascending gradients (i.e., $+6 \%$ gradient) the change in speed between the beginning and end of curve section is not substantial in the plot. Similar observations are also made in horizontal curves with descending gradients; however, these plots are not included in this paper for brevity.

Overall, it can be concluded that at milder gradient, curve radius influence vehicle speed, whereas, at steeper gradient, it is influenced by the gradient itself. Though not explored in this study, the curve length might also affect vehicle speed at the two ends of a curve. Further, as expected, the car speed is higher than the truck speed at the selected locations. To substantiate the above observations, detailed statistical analysis of curvature and gradient effect on vehicle speed are presented in the subsequent sections.

\section{Statistical Analysis of Mean Speed Data}

In this section the statistical parameters of vehicle speed data are analyzed. This is required to understand the field obtained speed data characteristics. It would provide indication to the quality of collected speed data and driving behavior at various locations within a curve. Further, these analyses would help in identifying the probable causes of inconsistency and possible safety improvements. The vehicle speed distributions at various locations are reviewed for normality using Anderson-Darling normality test. The obtained $p$ values from these tests are more than 0.05 indicating normally distributed speed data. Further, statistical parameters such as mean and standard deviation are estimated to understand the central tendency and dispersion of vehicle speed data. Table 3 lists the statistical parameter values of speed data at various locations. Following observations are made after comparing the field obtained car and truck speeds with roadway design speed (i.e., $50 \mathrm{kmph}$ ):

- Operating speed of about $45 \%$ cars is higher than the design speed.

- Average speed of cars is higher than the design speed at about $50 \%$ sites.

- Operating speed of approximately $10 \%$ trucks is higher than the design speed.

- Average speed of trucks is lower than the design speed at all sites.

The above observations imply that vehicles, particularly cars, are negotiating horizontal curves at a speed higher than the design speed. Therefore, a hypothesis test is conducted to examine if average vehicle speed within the curve is significantly greater than the design speed. This test is important to evaluate safety of the curve geometry and justify any requirement of speed calming measures. The hypothesis statements for this test are as follows:

$\mathrm{H}_{0}$ : Average speed is less or equal to design speed.

$\mathrm{H}_{1}$ : Average speed is more than design speed.

The results of the hypothesis test for car and truck at each location is shown in Table 4. It is observed that the 


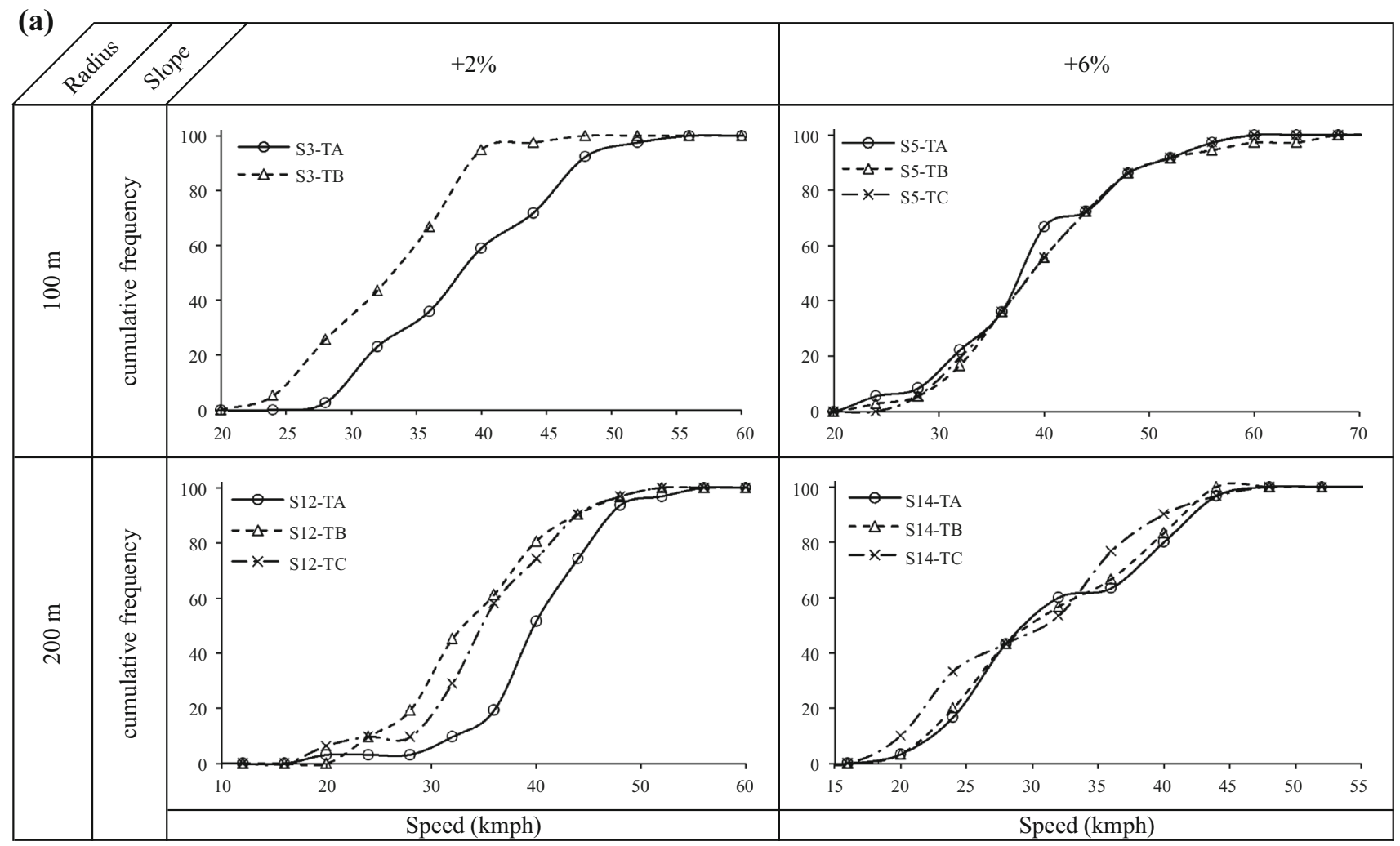

(b)

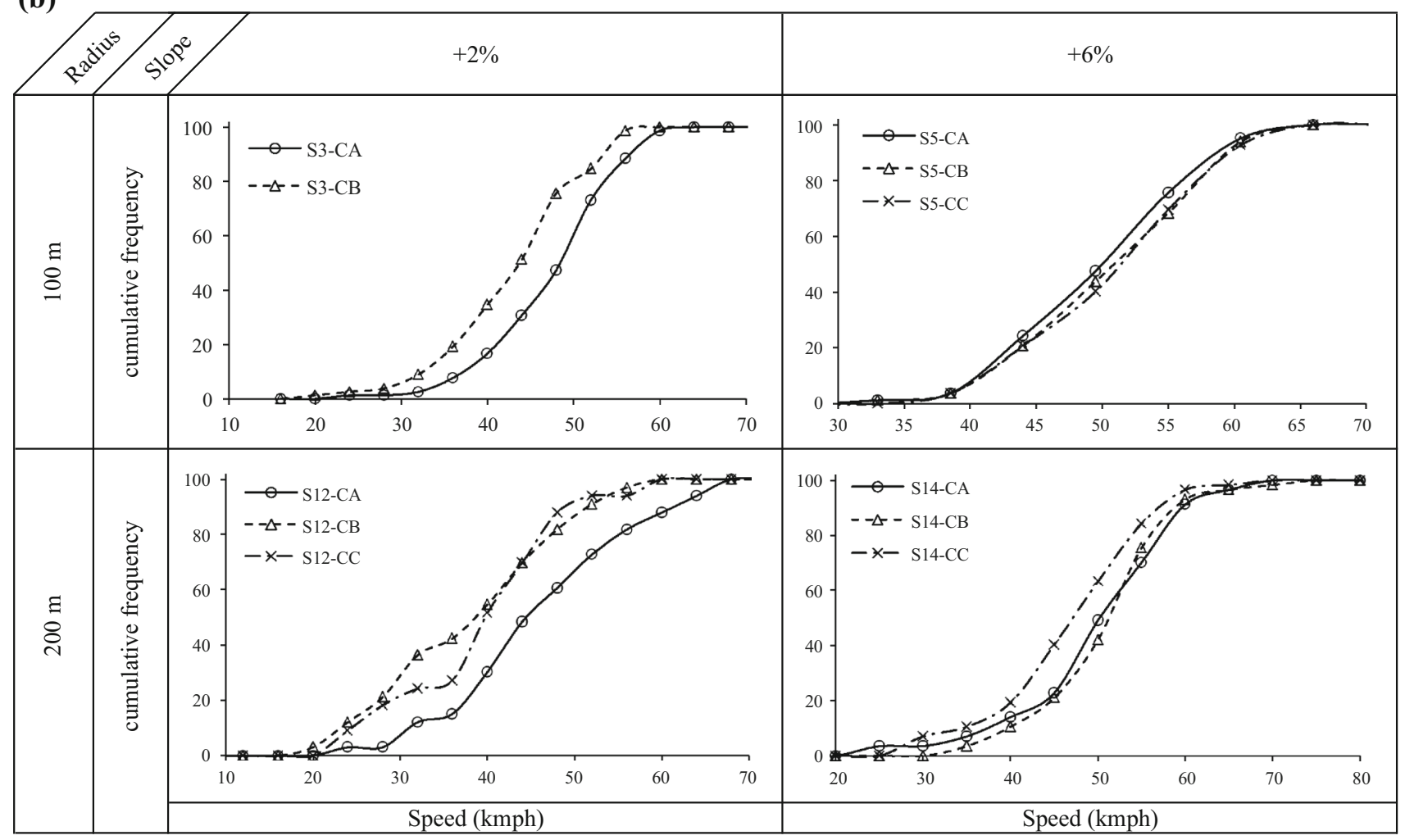

Fig. 3 a Cumulative truck speed frequency at four representative sites. b Cumulative car speed frequency at four representative sites 
Table 3 Speed statistics of car and truck at different locations

\begin{tabular}{|c|c|c|c|c|c|c|c|c|c|c|c|c|}
\hline \multirow[t]{3}{*}{ Site } & \multicolumn{6}{|c|}{ Car at location } & \multicolumn{6}{|c|}{ Truck at location } \\
\hline & \multicolumn{2}{|l|}{ A } & \multicolumn{2}{|l|}{ B } & \multicolumn{2}{|l|}{$\mathrm{C}$} & \multicolumn{2}{|l|}{ A } & \multicolumn{2}{|l|}{ B } & \multicolumn{2}{|l|}{$\mathrm{C}$} \\
\hline & $\mu$ & $\sigma$ & $\mu$ & $\sigma$ & $\mu$ & $\sigma$ & $\mu$ & $\sigma$ & $\mu$ & $\sigma$ & $\mu$ & $\sigma$ \\
\hline $\mathrm{S} 1$ & 48.9 & 7.79 & 39.5 & 6.53 & 33.7 & 5.60 & 36.2 & 7.57 & 31.0 & 6.37 & 27.8 & 5.35 \\
\hline $\mathrm{S} 2$ & NA & NA & 47.5 & 8.43 & 50.0 & 8.01 & NA & NA & 41.1 & 6.21 & 43.5 & 6.28 \\
\hline S3 & 47.8 & 7.55 & 43.1 & 7.85 & NA & NA & 39.0 & 6.92 & 33.1 & 5.84 & NA & NA \\
\hline S4 & 56.2 & 9.89 & 53.8 & 9.61 & 52.1 & 9.15 & 38.4 & 9.48 & 37.2 & 9.10 & 35.5 & 8.39 \\
\hline S5 & 49.9 & 7.09 & 50.8 & 7.13 & 51.0 & 7.18 & 39.1 & 8.24 & 40.3 & 8.74 & 40.0 & 7.95 \\
\hline S6 & 49.8 & 5.69 & 43.6 & 7.72 & 47.7 & 9.11 & 35.8 & 7.29 & 34.1 & 8.97 & 32.1 & 7.35 \\
\hline S7 & 54.3 & 7.17 & 47.8 & 8.68 & 58.2 & 8.43 & 36.1 & 6.06 & 29.0 & 5.37 & 39.5 & 7.24 \\
\hline S8 & 54.7 & 9.30 & NA & NA & 49.6 & 9.42 & 42.9 & 7.25 & NA & NA & 37.6 & 8.96 \\
\hline S9 & 52.1 & 8.05 & 54.4 & 8.39 & 56.8 & 8.37 & 39.7 & 9.31 & 39.9 & 8.80 & 40.7 & 9.55 \\
\hline S10 & 54.2 & 9.79 & 41.5 & 10.36 & 51.4 & 11.01 & 39.6 & 9.35 & 30.1 & 8.27 & 37.2 & 8.94 \\
\hline S11 & 59.6 & 11.17 & 53.4 & 10.90 & 53.6 & 10.50 & 48.8 & 8.15 & 46.4 & 7.68 & 43.4 & 6.84 \\
\hline S12 & 45.8 & 10.92 & 38.0 & 10.62 & 39.9 & 9.44 & 40.0 & 7.25 & 34.6 & 7.33 & 35.6 & 7.36 \\
\hline S13 & 60.9 & 9.51 & 57.7 & 9.95 & 56.3 & 10.20 & 46.2 & 6.73 & 43.3 & 6.91 & 40.1 & 8.27 \\
\hline S14 & 50.1 & 8.94 & 51.3 & 7.75 & 46.6 & 8.75 & 32.1 & 8.18 & 31.6 & 7.42 & 30.2 & 7.63 \\
\hline S15 & 58.2 & 8.33 & 58.7 & 9.04 & 63.8 & 9.88 & 42.2 & 10.58 & 40.8 & 11.21 & 45.8 & 11.10 \\
\hline S16 & 52.6 & 9.62 & 47.7 & 10.20 & 47.9 & 10.70 & 41.7 & 6.97 & 37.2 & 5.84 & 38.1 & 8.01 \\
\hline
\end{tabular}

All data in kmph

NA, data not available, $\mu$, mean speed, $\sigma$, standard deviation of speed
Table 4 Reject null hypothesis for safe average speed

\begin{tabular}{|c|c|c|c|c|c|c|}
\hline \multirow[t]{2}{*}{ Site } & \multicolumn{3}{|c|}{ Car at location } & \multicolumn{3}{|c|}{ Truck at location } \\
\hline & A & B & $\mathrm{C}$ & A & B & $\mathrm{C}$ \\
\hline S1 & No & No & No & No & No & No \\
\hline S2 & NA & No & No & NA & No & No \\
\hline S3 & No & No & NA & No & No & NA \\
\hline S4 & Yes & Yes & Yes & No & No & No \\
\hline S5 & No & No & No & No & No & No \\
\hline S6 & No & No & No & No & No & No \\
\hline S7 & Yes & No & Yes & No & No & No \\
\hline S8 & Yes & NA & No & No & NA & No \\
\hline S9 & Yes & Yes & Yes & No & No & No \\
\hline S10 & Yes & No & No & No & No & No \\
\hline S11 & Yes & Yes & Yes & No & No & No \\
\hline $\mathrm{S} 12$ & No & No & No & No & No & No \\
\hline S13 & Yes & Yes & Yes & No & No & No \\
\hline S14 & No & No & No & No & No & No \\
\hline S15 & Yes & Yes & Yes & No & No & No \\
\hline S16 & Yes & No & No & No & No & No \\
\hline
\end{tabular}

NA, data not available

null hypothesis is accepted for trucks at all locations. In other words, the average speed of trucks at all the locations is less than the design speed. It is also observed that the average speeds of cars at some curves are higher than the design speed of that curve. In other words, car speed at these locations is not in conformation with design speed and hence, requires speed-calming measure to curb car speed for safety. The rejection rate of null hypothesis for car speeds at the beginning of a curve (i.e., location A) are $60 \%$ and at other locations (i.e., B and C) is $35 \%$. This indicates that cars are often operating at higher speeds at the beginning of the curve and tend to lower the speed at the middle and end of the curve. Therefore, a hypothesis test is performed at a confidence interval of $95 \%$ to examine the difference in mean speeds among cars as well as trucks between the three locations A, B and C (refer Fig. 1 for locations) of each site (i.e., S1 to S16). The hypothesis statements for this analysis are as follows:

$\mathrm{H}_{0}$ : mean speeds are same i.e., $\left(\mu_{0}=\mu_{1}\right)$ between a pair of location (such as, $\mathrm{A}-\mathrm{B}, \mathrm{B}-\mathrm{C}$ and $\mathrm{A}-\mathrm{C}$ ) in a curve.

$\mathrm{H}_{1}$ : mean speeds are significantly different i.e., $\left(\mu_{0} \neq \mu_{1}\right)$ between a pair of location (such as, A-B, B-C and $\mathrm{A}-\mathrm{C}$ ) in a curve.

The hypothesis is examined using the t-score test statistics, which can be defined by Eq. 1. The obtained results are tabulated in Table 5.

$t=\left[\left(\mu_{0}-\mu_{1}\right)-d\right] / e$ 
Table 5 Reject null hypothesis for mean speed variation

\begin{tabular}{|c|c|c|c|c|c|c|c|c|c|}
\hline \multirow[t]{2}{*}{ Site } & \multicolumn{9}{|l|}{ Locations } \\
\hline & CA vs. CB & CA vs. CC & CB vs. $\mathrm{CC}$ & TA vs. TB & TA vs. TC & TB vs. TC & CA vs. TA & CB vs. TB & $\mathrm{CC}$ vs. TC \\
\hline S1 & Yes & Yes & No & Yes & Yes & No & Yes & Yes & Yes \\
\hline S4 & No & Yes & No & No & No & No & Yes & Yes & Yes \\
\hline S5 & Yes & Yes & No & Yes & Yes & No & Yes & No & No \\
\hline S6 & No & No & No & No & No & No & Yes & Yes & Yes \\
\hline S7 & No & Yes & Yes & No & No & No & Yes & Yes & Yes \\
\hline S9 & No & Yes & Yes & No & No & No & Yes & Yes & Yes \\
\hline S10 & No & Yes & No & No & Yes & No & Yes & Yes & Yes \\
\hline S11 & Yes & Yes & No & No & Yes & No & Yes & Yes & Yes \\
\hline S12 & Yes & No & Yes & Yes & No & Yes & Yes & Yes & Yes \\
\hline S13 & Yes & No & Yes & No & Yes & No & Yes & Yes & Yes \\
\hline S14 & Yes & Yes & Yes & Yes & Yes & Yes & Yes & Yes & Yes \\
\hline S15 & No & Yes & No & No & No & No & Yes & Yes & Yes \\
\hline S16 & Yes & Yes & Yes & Yes & Yes & Yes & Yes & Yes & Yes \\
\hline
\end{tabular}

CA, CB and CC are mean car speeds at location A, B and C. Similarly, TA, TB and TC are mean truck speeds at location A, B and C

where,

$\mu_{0}, \mu_{1}=$ Mean speeds at a pair of location in a curve.

$d=$ Expected difference in population means at $95 \%$ confidence interval.

$e=$ Standard error.

The following conclusions are drawn by analyzing the results in Table 5:

(i) The null hypothesis is rejected when mean car and truck speeds are compared at different locations (i.e., A, B and C in Fig. 1) of almost all sites. See columns CA vs TA, CB vs. TB and CC vs. TC of Table 3 for details. This implies that car and truck operate at different speeds in these locations.

(ii) The geometric features at each location (provided in Table 2) are compared with the hypothesis results in Table 5. It is observed that as gradient increases, the probability of $\mathrm{H}_{0}$ rejection decreases. It implies that vehicle speed at various locations in the curves (i.e., A, B and C of Fig. 1) reduces with increase in gradient. This is prominent for trucks as they maintain lower speed compared to the cars. It supports the observation discussed in the previous section. The probability of $\mathrm{H}_{0}$ rejection is further reduced on ascending gradients.

The results presented in Table 5 are further summarized in Table 6 for all locations with ascending and descending gradients. This table indicates the percentage of cases where null hypothesis i.e., $\left(\mu_{0}=\mu_{1}\right)$ is rejected. The following conclusions are made from Table 6:

1. The difference in speeds for both cars and trucks at different locations in a curve is high for sites with descending gradient. The descending gradient might be helping vehicle to accelerate between the locations.

2. In this table, the combined effect of curve and gradient are considered. In case of ascending gradient, vehicles use more power to overcome the effect of the ascending gradient. Hence, the vehicle speed difference at entry (i.e., location A) and middle (i.e., location B) of the curve $\left(\mathrm{H}_{0}\right.$ is rejected for $37 \%$ of cars and trucks) is not significant. Similar trend is observed at
Table 6 Percentage of null hypothesis rejected for each location at all sites

\begin{tabular}{|c|c|c|c|c|c|c|c|c|c|c|c|c|}
\hline \multirow[t]{3}{*}{$\mu_{1}$} & \multicolumn{12}{|l|}{$\mu_{0}$} \\
\hline & \multicolumn{6}{|c|}{ Descending gradient sites } & \multicolumn{6}{|c|}{ Ascending gradient sites } \\
\hline & CA & CB & $\mathrm{CC}$ & TA & TB & $\mathrm{TC}$ & CA & $\mathrm{CB}$ & $\mathrm{CC}$ & TA & TB & TC \\
\hline CA & - & & & & & & - & & & & & \\
\hline $\mathrm{CB}$ & 80 & - & & & & & 37 & - & & & & \\
\hline $\mathrm{CC}$ & 60 & 80 & - & & & & 87 & 25 & - & & & \\
\hline TA & 100 & 80 & 100 & - & & & 100 & 87 & 87 & - & & \\
\hline TB & 100 & 100 & 100 & 40 & - & & 100 & 87 & 100 & 37 & - & \\
\hline TC & 100 & 100 & 100 & 60 & 40 & - & 100 & 87 & 87 & 50 & 12 & - \\
\hline
\end{tabular}


middle (i.e., location B) and exit (i.e., location C) of the curve $\left(\mathrm{H}_{0}\right.$ is rejected for $25 \%$ of cars and $12 \%$ of trucks). However, comparing the speed difference between the entry (i.e., location A) and exit (i.e., location C) only, the rejection rate for the null hypothesis is significant $\left(\mathrm{H}_{0}\right.$ is rejected for $87 \%$ of cars and $50 \%$ trucks). Again this is prominent for cars compared to trucks and is in conformation with the conclusion on the amount of speed dispersion of cars and heavy vehicles [14].

\section{Statistical Analysis of Operating Speed (i.e., 85th Percentile Vehicle Speed)}

The safety evaluation and design consistency criteria are based on operating speed (see Table 1). Hence, the statistical analyses of vehicle operating speed or the 85th percentile speed of cars and trucks at various locations are needed. This would help in identifying the inconsistent sections. Further it can help reviewing the consistency in speed data collected from various sites having similar geometric properties. A preliminary analysis is conducted by separately plotting the 85 th percentile speed of cars and trucks at location $\mathrm{A}, \mathrm{B}$, and $\mathrm{C}$ for all sites with ascending and descending gradients (refer Fig. 4). From this figure it is observed that at almost all sites with ascending gradient, the 85th percentile car and truck speed decreases from location A to C. However, at almost all sites with descending gradient, the 85th percentile car and truck speed decreases from location A to B and then increases from location B to C. This might be explained with the help of perceived sight distance. While approaching location B, from $\mathrm{A}$, the perceived sight distance reduces due to the curvature. Thus, drivers choose to decelerate while moving from location A to B. However, beyond location B, the perceived sight distance gradually improves (due to the approaching tangent section at location C) and the descending gradient assists in vehicle acceleration. Thus, drivers choose to accelerate while moving away from location B, toward location C. However, in some sites, this trend is not observed. Adjacent horizontal curve in the following section might be the reason for this.

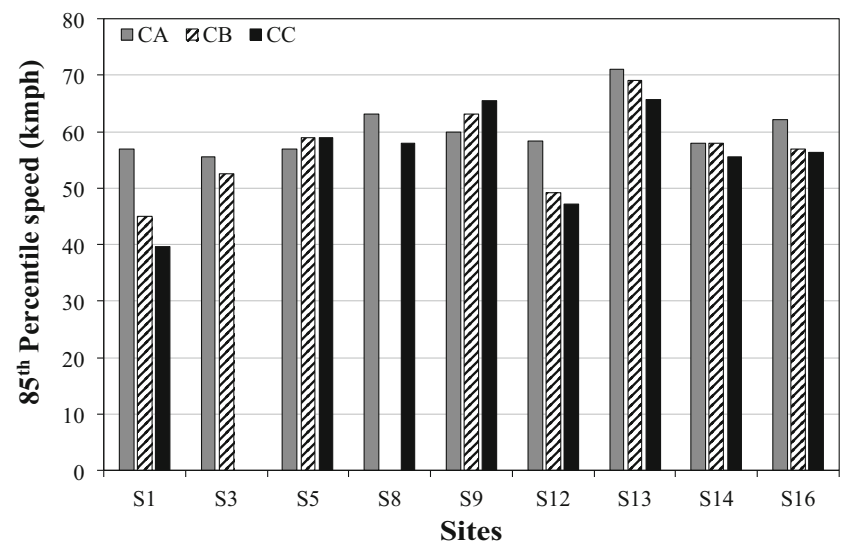

(a) Car on ascending gradient sites

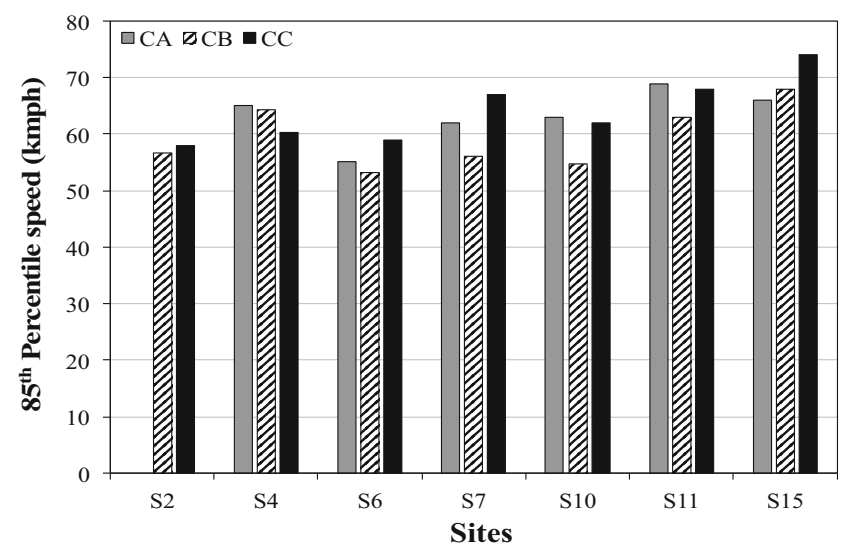

(c) Cars on descending gradient sites

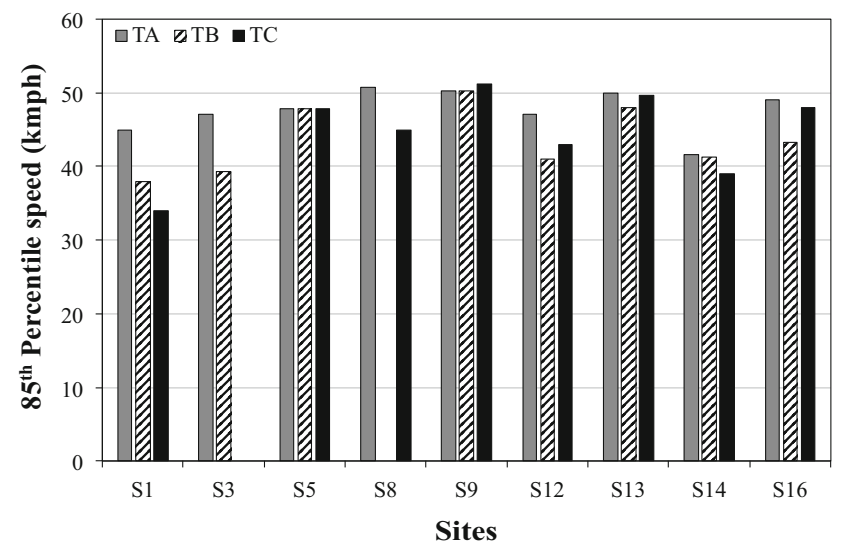

(b) Trucks on ascending gradient sites

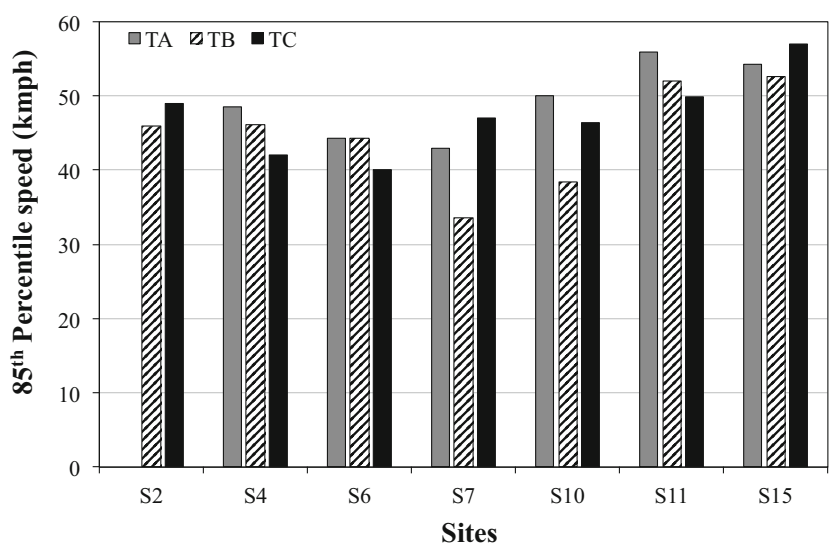

(d) Trucks on descending gradient sites

Fig. 4 The 85th percentile speed at location $A, B$ and $C$ of all sites 
Table 7 Reject null hypothesis for 85th percentile speed variation

\begin{tabular}{|c|c|c|c|c|c|}
\hline \multirow[t]{2}{*}{ Site } & \multicolumn{5}{|l|}{ Locations } \\
\hline & CA vs. C B & $\mathrm{CB}$ vs. $\mathrm{CC}$ & TA vs. TB & TB vs. TC & $\mathrm{CB}$ vs. TB \\
\hline S1 & Yes & Yes & Yes & Yes & Yes \\
\hline $\mathrm{S} 2$ & NA & No & NA & No & Yes \\
\hline S3 & No & Yes & Yes & Yes & Yes \\
\hline S4 & No & No & No & No & Yes \\
\hline S5 & No & No & No & No & Yes \\
\hline S6 & No & Yes & No & No & Yes \\
\hline S7 & Yes & Yes & Yes & Yes & Yes \\
\hline S8 & NA & NA & NA & NA & NA \\
\hline S9 & No & No & No & No & Yes \\
\hline S10 & Yes & Yes & Yes & Yes & Yes \\
\hline S11 & No & No & No & No & Yes \\
\hline S12 & Yes & No & No & No & Yes \\
\hline S13 & No & No & No & No & Yes \\
\hline S14 & No & No & No & No & Yes \\
\hline S15 & No & Yes & No & No & Yes \\
\hline S16 & No & No & Yes & No & Yes \\
\hline
\end{tabular}

CA, CB and CC are 85th percentile car speed at location A, B and C. Similarly, TA, TB and TC are 85th percentile truck speed at location $\mathrm{A}, \mathrm{B}$ and $\mathrm{C}$

NA, data not available

Further, hypothesis test is conducted at $95 \%$ confidence interval to examine the variations of 85 th percentile car and truck speeds between the three locations of each site. The adopted method is similar to the one proposed by Hou et al. [21]. In this case, the null hypothesis is represented as:

$H_{0}:\left(\zeta_{0.85}\right)_{X}-\left(\zeta_{0.85}\right)_{Y}=0$

The hypothesis is examined using the random variable given in Eq. 3 and the obtained results are shown in Table 7.

$\frac{\left(X_{([n 0.85]+1)}-Y_{([n 0.85]+1)}\right)-0}{1.53 \sqrt{S_{X}^{2} / n_{X}+S_{Y}^{2} / n_{Y}}}$

where,

$\left(\zeta_{0.85}\right)_{X}=$ The 85th distribution quantiles of sample $X$.

$\left(\zeta_{0.85}\right)_{Y}=$ The 85 th distribution quantiles of sample $Y$.

$X_{([n 0.85]+1)}=$ The 85 th sample quantiles of sample size $n_{X}$.

$Y_{([n 0.85]+1)}=$ The 85 th sample quantiles of sample size $n_{Y}$.

$S_{X}=$ Standard deviation of sample $X$.

$S_{Y}=$ Standard deviation of sample $Y$.

It is observed from Table 7 that about $25-40 \%$ of the sites have statistically different 85 th percentile speed between locations $\mathrm{A} \& \mathrm{~B}$, and $\mathrm{B} \& \mathrm{C}$. The null hypothesis is rejected for approximately $60 \%$ locations belonging to sites with gradients ranging between \pm 4 percentages. Whereas, the null hypothesis is rejected for $10 \%$ locations belonging to sites with steeper gradients (i.e., gradient $>4 \%$ or gradient $<-4 \%$ ). Driver discomfort and inability to accelerate at steeper gradients could be the reasons behind this. It is also observed that the 85th percentile speed of cars and trucks at the middle of a curve is statistically different. It is possibly due to the difference in maneuverability and lurch among cars and trucks.

\section{Evaluation of Design Consistency}

The geometric design consistency and safety level of design are evaluated using models suggested by Lamm et al. [15] and Fitzpatrick et al. [16] (see Table 1). The design safety rating of all study sites is summarized in Table 8. It is observed from this table that about $7 \%$ locations based on Criteria I and about $21 \%$ locations based on Criteria II are rated as fair. These ratings can be improved by adopting speed-calming measures or by altering geometric features. It helps in managing safety by keeping the operating speed at or below the design speed considered. The design consistency evaluation criteria by Lamm et al. [15] and Fitzpatrick et al. [16] are established for homogeneous traffic with strong lane discipline. There is a need to develop reliable geometric design consistency evaluation criteria for Indian traffic condition.

\section{Conclusions}

Frequent horizontal curves with gradients are common in roadways located in mountainous terrain. This study attempts to understand the driving behavior of Indian 
Table 8 Design safety level

\begin{tabular}{|c|c|c|c|c|c|c|c|c|c|c|}
\hline \multirow[t]{2}{*}{ Site } & \multicolumn{6}{|c|}{ CRITERIA I $\left(\mathrm{V}_{85}-\mathrm{V}_{\mathrm{d}}\right)$} & \multicolumn{4}{|c|}{ CRITERIA II $\left(\lambda \mathrm{V}_{85}\right)$} \\
\hline & CA & $\mathrm{CB}$ & $\mathrm{CC}$ & TA & $\mathrm{TB}$ & $\mathrm{TC}$ & $\mathrm{V}_{85|C B-C A|}$ & $\mathrm{V}_{85|C C-C B|}$ & $\mathrm{V}_{85 \mid \mathrm{TB}-\mathrm{TAl}}$ & $\mathrm{V}_{85|T C-T B|}$ \\
\hline S1 & G & G & G & G & G & G & $\mathrm{F}$ & G & G & G \\
\hline S2 & NA & G & G & NA & G & G & NA & G & NA & G \\
\hline S3 & G & G & NA & G & G & NA & G & NA & G & NA \\
\hline S4 & G & $\mathrm{F}$ & $\mathrm{G}$ & $\mathrm{F}$ & G & G & G & $\mathrm{G}$ & G & G \\
\hline S5 & G & G & G & G & G & G & G & G & G & G \\
\hline S6 & G & G & $\mathrm{F}$ & G & $\mathrm{F}$ & G & G & G & G & G \\
\hline S7 & G & G & G & G & G & G & G & F & G & $\mathrm{F}$ \\
\hline S8 & G & NA & G & G & NA & G & NA & NA & NA & NA \\
\hline S9 & G & G & G & F & $\mathrm{F}$ & F & G & G & G & G \\
\hline S10 & G & $\mathrm{F}$ & F & $\mathrm{F}$ & G & G & G & G & F & G \\
\hline S11 & G & G & F & G & G & G & G & G & G & G \\
\hline S12 & F & F & G & G & G & G & G & G & G & G \\
\hline S13 & $\mathrm{F}$ & F & G & G & G & G & G & G & G & G \\
\hline S14 & G & G & G & G & G & G & G & G & G & G \\
\hline S15 & G & G & F & $\mathrm{F}$ & $\mathrm{F}$ & $\mathrm{F}$ & G & G & G & G \\
\hline S16 & G & G & G & G & G & G & G & G & G & G \\
\hline
\end{tabular}

G, good, F, fair and NA, not available

drivers on roadways located in mountainous terrain. The combined effect of vertical and horizontal gradient is investigated on multiple road sites of NH-40 in Northeast region of India. Statistical analysis of the data produced several useful findings about vehicle speed in curve sections. As part of geometric design consistency evaluation criteria, the 85th percentile vehicle speed is adopted to compare it with the roadway design speed. The comparisons suggest that about $45 \%$ cars are operating at speed higher than the design speed. Additionally, the average speed of cars is more than the design speed at $50 \%$ of the sites. In case of trucks, this is about $10 \%$. This is a serious safety concern. Further study is required to identify a way to contain the vehicle operating speed within the design speed. Various engineering measures such as transverse rumble strips, transverse markings, speed feedback sign, lane narrowing, etc. have proven track record in reducing vehicle speed in high-speed roadways.

It is interesting to note that the effect of curve on operating speed is significant at flatter gradient. However, at steeper gradient, the operating speed is influenced by the gradient itself. Also, car and truck speeds are found to be different on curves in most of the cases. This difference in vehicle's speed (both car and truck) at different locations of the curves (i.e., entry, middle and exit locations) is prominent in case of descending gradient as it helps vehicle to accelerate between the entry and exist locations of a curve. It is also observed that geometric features of neighboring section can influence vehicle speed at a horizontal curve. Therefore, analysis of adjacent horizontal curves as an integrated system may provide better insight at some locations. This kind of study may help in enhancing the existing safety evaluation criteria of a roadway and to decide suitable measures to improve roadway safety in mountainous terrain.

Out of all the locations examined in this study, it is identified that $7 \%$ locations based on Criteria I and $21 \%$ locations based on Criteria II are rated fair. The safety implication of this rating needs to be substantiated with the help of crash data. Also, the design consistency and safety evaluation criteria (i.e., Criteria I and II) need validation for Indian driving conditions. The vehicle speed characteristics obtained in this study are indicative and can be used in developing speed prediction models for various roadway geometric features. However, this would require more data from various locations. These are some of the future scope of this work.

\section{References}

1. Ng JC, Sayed T (2004) Effect of geometric design consistency on road safety. Can J Civ Eng 31(2):218-227

2. Choi J, Lee J, Lee S (2001) Improvement of highway design consistency evaluation procedure. J East Asia Soc Transp Stud 4(1):365-380

3. Polus A, Fitzpatrick K, Fambro DB (2000) Predicting operating speeds on tangent sections of two-lane rural highways. Transp Res Rec J Transp Res Board 1737(1):50-57

4. Jacob A, Anjaneyulu MVLR (2012) Operating speed of different classes of vehicles at horizontal curves on two-lane rural highways. J Transp Eng 139(3):287-294

5. Praticò FG, Giunta M (2012) Modeling operating speed of two lane rural roads. Proc Soc Behav Sci 53:664-671 
6. Krammes RA (2000) Design speed and operating speed in rural highway alignment design. Transp Res Rec J Transp Res Board 1701(1):68-75

7. Hassan Y, Easa SM (2003) Effect of vertical alignment on driver perception of horizontal curves. J Transp Eng 129(4):399-407

8. Fitzpatrick K et al (2000) Speed prediction for two-lane rural highways, FHWA-RD-99-171. U.S. Department of Transportation, Washington, DC

9. Misaghi P, Hassan Y (2005) Modeling operating speed and speed differential on two-lane rural roads. J Transp Eng 131(6):408-418

10. Hassan Y, Sarhan M (2011) Modeling operating speed. Transportation research circular, E-C151, Federal Highway Administration, Transportation Research Board, Washington, DC

11. Findley DJ, Hummer JE, Rasdorf W, Zegeer CV, Fowler TJ (2012) Modeling the impact of spatial relationships on horizontal curve safety. Accid Anal Prev 45:296-304

12. Poe CM, Tarris JP, Mason JM Jr (1996) Relationship of operating speed to roadway geometric design speed. Report No. FHWARD-96-024. Federal Highway Administration, U.S. Department of Transportation, Washington, D.C

13. Hashim IH, Abdel-Wahed TA (2012) Effect of highway geometric characteristics on capacity loss. J Transp Syst Eng Inf Technol 12(5):65-75

14. Mehar A, Chandra S, Velmurugan S (2013) Speed and acceleration characteristics of different types of vehicles on multi-lane highways. Eur Transp 55:1825-3997
15. Lamm R, Psarianos B, Mailaender T (1999) Highway design and traffic safety engineering handbook. McGraw-Hill Companies, Inc., New York

16. Fitzpatrick K et al (2000) Evaluation of design consistency methods for two-lane rural highways, executive summary, report no. FHWA-RD-99-173. Federal Highways Administration

17. Jacob A, Dhanya R, Anjaneyulu MVLR (2013) Geometric design consistency of multiple horizontal curves on two-lane rural highways. Proc Soc Behav Sci 104:1068-1077

18. Pérez-Zuriaga AM, Camacho-Torregrosa FJ, García A (2013) Tangent-to-curve transition on two-lane rural roads based on continuous speed profiles. J Transp Eng 139(11):1048-1057

19. Camacho-Torregrosa FJ, Pérez-Zuriaga AM, Campoy-Ungría JM, García-García A (2013) New geometric design consistency model based on operating speed profiles for road safety evaluation. Accid Anal Prev 61:33-42

20. Indian Roads Congress (1980) IRC: 73-1980, geometric design standards for rural (non-urban) highways. The Indian Roads Congress, New Delhi

21. Hou Y, Sun C, Edara P (2012) A statistical test for 85th and 15th percentile speeds using the asymptotic distribution of sample quantiles. Transp Res Rec J Transp Res Board 2279:47-53 